\title{
Article \\ Effect of Calcium Carbonate Particle Size on the Scratch Resistance of Rapid Alkyd-Based Wood Coatings
}

\author{
Orkun Ersoy ${ }^{1, * \mathbb{D}}$, Sinan Fidan $\left.{ }^{2} \mathbb{(}\right)$, Harun Köse ${ }^{3}$, Dilek Güler $^{3}$ and Ömer Özdöver ${ }^{3}$ \\ 1 Department of Geological Engineering, Faculty of Engineering, Hacettepe University, 06800 Ankara, Turkey \\ 2 Faculty of Aeronautics and Astronautics, Kocaeli University, 41285 Kocaeli, Turkey; sfidan@kocaeli.edu.tr \\ 3 R\&D Department, Niğtaş Corporation, 51100 Niğde, Turkey; argemuduru@nigtas.com (H.K.); \\ arge2@nigtas.com (D.G.); arge4@nigtas.com (Ö.Ö.) \\ * Correspondence: oersoy@hacettepe.edu.tr
}

check for updates

Citation: Ersoy, O.; Fidan, S.; Köse, H.; Güler, D.; Özdöver, Ö. Effect of Calcium Carbonate Particle Size on the Scratch Resistance of Rapid Alkyd-Based Wood Coatings. Coatings 2021, 11, 340. https:// doi.org/10.3390/coatings11030340

Academic Editor: Véronic Landry

Received: 13 February 2021

Accepted: 15 March 2021

Published: 17 March 2021

Publisher's Note: MDPI stays neutral with regard to jurisdictional claims in published maps and institutional affiliations.

Copyright: (c) 2021 by the authors. Licensee MDPI, Basel, Switzerland. This article is an open access article distributed under the terms and conditions of the Creative Commons Attribution (CC BY) license (https:// creativecommons.org/licenses/by/ $4.0 /)$.

\begin{abstract}
Polymer-based wood coatings are used for aesthetic purposes as well as to protect wood surfaces, especially under external conditions. High-hardness mineral fillers are thought to enhance the resistance of these polymer coatings to wear and scratching. However, recent studies suggest that the relatively low-hardness mineral calcite $\left(\mathrm{CaCO}_{3}\right.$, Mohs hardness of 3) performs similarly to harder minerals under external conditions. It can replace more expensive hard minerals, thus driving research interest in its use. In this study, $\mathrm{CaCO}_{3}$ powders with different grain sizes were applied to rapid alkyd-based coating formulations, and the effect of $\mathrm{CaCO}_{3}$ particle size on the scratch behavior of the coatings was investigated under identical test conditions. The scratch morphologies, scratch hardness, and roughness values of the scratched surfaces indicated that the surfaces of the rapid alkydbased wood coatings including finer-grained $\mathrm{CaCO}_{3}$ experienced plastic plowing-type deformation in the form of regular, narrow, and shallow scratches, showing high scratch resistance. Coatings using coarser-grained $\mathrm{CaCO}_{3}$ experienced more extensive plastic deformation of the plowing-tearing type owing to the weaker filler-polymer interface and the breakage of larger coating pieces from the coating surface.
\end{abstract}

Keywords: wood coating; filler; calcium carbonate; calcite; alkyd resin; scratch hardness

\section{Introduction}

Wood has been used by people for various purposes for thousands of years. Because of its ease of production, abundance, and economy, it is a favored material. It is used in interior and exterior applications owing to its durability, strength, lightness, and texture. However, it should be protected with a coating to prevent it from damage, especially under external conditions [1]. Polymer coatings such as varnishes have been explored as possible protective measures [2].

Varnish is a blend of oils and resins that coats the surface of wood; it provides a transparent and protective coating [3]. Today, commercial varnishes use acrylic, alkyd, or polyurethane resins to produce a clear, translucent, and hard protective finish in the form of a film on the wood. Hybrid alkyd resins are resistant to solvents, moisture, and ultraviolet (UV) light, but they are relatively soft like many polymers, and their surfaces can be scratched [4]. However, high resistance to scratching and abrasion is expected from polymer wood coatings [5-7].

Tensile tears can occur on the scratched surface when the tensile stress exceeds the surface tensile strength or the surface crazing tension of the polymer. Consequently, the polymer surface experiences cracking and/or crazing. These fracture features can drastically increase the light-scattering ability of the surface, causing whitening and increased scratch visibility [8]. Efforts to increase the scratch resistance of polymers are becoming increasingly widespread, and the number of studies on this matter is increasing [8-11]. Two methods have been proposed to increase the scratch resistance of polymer coatings. 
The first is to optimize the polymer lacquer components for this purpose; the second is to reinforce the coating by adding fillers [9]. The scratch resistance of a material can be improved by increasing its hardness. High-hardness mineral fillers are therefore thought to enhance the resistance of polymers to wear and scratching [1].

Fillers added to polymers are mainly of two types: naturally originating (mineral) and synthetic fillings [12]. Mineral fillings can be further subdivided into rocks and minerals. Many studies have been conducted on the effects of synthetic fillers on the scratch resistance of polymers [13-19]. The use of natural mineral fillings is growing continuously because of their abundance on the earth, low cost, and lower probability of harming nature and living creatures compared to synthetic fillers during their production and application. Minerals such as talc [8,20-22], wollastonite [20,21,23], calcite (calcium carbonate; $\mathrm{CaCO}_{3}$ ) [1,24-31], montmorillonite (a nano-clay) [32-34], and baryte [34] have been added to thermoplastic olefins and various polymer coatings to determine their effects on wear and scratch resistance. Nepheline syenite, an igneous rock that mainly comprises nepheline (feldspathoid) and alkali feldspar minerals, was tested in terms of its effect on the corrosion of acrylic coatings [35]. Alkali feldspars and feldspathoids are minerals with Mohs scale hardness values of 6-6.5. However, the hardness needed to withstand wear and scratching can cause application problems. Harder materials are more difficult to disperse in mixtures, and their use has disadvantages owing to the abrasion of the mixing blades and other equipment (e.g., pumps and spray tips) used in the process [36].

$\mathrm{CaCO}_{3}$, an important rock-forming mineral in sedimentary environments, can be mined and ground into micrometer-sized particles called ground calcium carbonate (GCC) [27]. GCC is used as a filler in many polymer composites because it is nontoxic, tasteless, nonirritating, cheap, and abundant as a resource. It is one of the most commonly used fillers in wood coatings [1,29-31]. Precipitated $\mathrm{CaCO}_{3}$ (PCC) is the synthetic form of calcite, formed by hydrating high-calcium quicklime and then allowing the resulting slurry or "milk-of-lime" to react with carbon dioxide. Because it has low acid resistance and abrasion resistance as a carbonate mineral with a low Mohs scale hardness of 3, it is not particularly preferred in coatings used outdoors. However, some experimental studies have shown that $\mathrm{CaCO}_{3}$, which is much cheaper than feldspar and feldspathoids, can be substituted for these minerals in coating formulations and even outperform them in some physical properties. Raper and Skelhorn [36] stated that, in coatings with added feldspar, feldspathoid, or $\mathrm{CaCO}_{3}$ of equivalent particle size and volumetric loading, $\mathrm{CaCO}_{3}$ maintained and even improved some properties of the coating. $\mathrm{CaCO}_{3}$ has performed similarly to other minerals, particularly in simulated external conditions, and has disproven the perceived differences among these minerals. These results suggest that $\mathrm{CaCO}_{3}$ can be used to replace feldspar and feldspathoids to reduce costs [36].

Factors affecting the scratch behavior of polymers can be classified into two main groups [37]: (i) testing conditions such as indenter geometry [38-40], normal load [38,39,41,42], temperature [11,40], and scratch velocity [38-40]; and (ii) material properties such as modulus [43-45], yield stress [44], ductility [46,47], crystallinity [48,49], hardness [44,50], surface roughness [51], and surface tension [52]. In this study, $\mathrm{CaCO}_{3}$ powders of different grain sizes were applied to rapid alkyd-based coating formulations, and the effect of $\mathrm{CaCO}_{3}$ particle size on the scratch behavior of the coatings was investigated under identical test conditions.

\section{Materials and Methods}

Niğ Taş Corporation (Niğde, Turkey) supplied ground micronized $\mathrm{CaCO}_{3}$ in four different particle sizes of high purity and whiteness. The rapid alkyd resin, solvent mixture (white spirit), lecithin, antisetting agent (Texaphor), and rheological additive (Viscogel ED) were obtained from Asil Kimya (Istanbul, Turkey).

Four rapid alkyd-based coatings including $\mathrm{CaCO}_{3}$ with different grain sizes and one $\mathrm{CaCO}_{3}$-free coating were prepared by the solution blending method according to the formulation given in Table 1. The rapid alkyd resin was mixed with a multipurpose 
disperser (VBR-12, Yokes, İzmir, Turkey) for $2 \mathrm{~min}$ at $1500 \mathrm{rpm}$. The resin was blended with white spirit, lecithin, and Texaphor and mixed for $3 \mathrm{~min}$. Viscogel ED was added to the mixture, which was then mixed for a further $5 \mathrm{~min} . \mathrm{CaCO}_{3}$ was added to the mixture, and the combination was blended at $2000 \mathrm{rpm}$ for $10 \mathrm{~min}$. This last step was not performed in the preparation of the $\mathrm{CaCO}_{3}$-free coating. Precisely $25 \%$ calcite by weight was added to the formulation, considering the previous studies $[27,36]$ and low-cost expectation of the manufacturers.

Table 1. Formulation for the alkyd-based wood coating.

\begin{tabular}{cc}
\hline Material & $\%$ \\
\hline Rapid alkyd resin & 60 \\
Solvent mixture (white spirit) & 13.2 \\
Lecithin & 0.4 \\
Antisetting agent (Texaphor) & 0.6 \\
Rheology additive (Viscogel ED) & 0.8 \\
$\mathrm{CaCO}_{3}$ & 25 \\
\hline
\end{tabular}

Once the prepared coatings reached room temperature, the viscosity was measured with the assistance of a Krebs Stormer viscometer (480, Sheen, Herefordshire, UK). The prepared coatings were applied with the help of a film applicator to glass surfaces with a thickness of $200 \mu \mathrm{m}$.

The particle size distributions of the $\mathrm{CaCO}_{3}$ powder samples were analyzed using a laser particle size diffraction analyzer (Mastersizer 2000, Malvern Instruments Ltd., Worcestershire, UK). The color of the powders was determined using a color spectrophotometer (Elrepho, DataColor, Lawrenceville, NJ, USA). As defined by the Commission Internationale de $l^{\prime}$ Eclairage (CIE), $L^{*}$ indicates lightness, $a^{*}$ is the red/green coordinate, and $b^{*}$ is the yellow/blue coordinate [53]. Brunauer-Emmett-Teller (BET) measurements were used to assess the precise surface areas of the $\mathrm{CaCO}_{3}$ powders using a surface-area analyzer (Quadrasorb-evo, Quantachrome, Boynton Beach, FL, USA). The oil absorption values of the $\mathrm{CaCO}_{3}$ powder samples were determined according to the ASTM D 281 standard [54]. A stiff, putty-like paste was formed by the dropwise addition of dioctyl phthalate (DOP) oil or flax oil to $\mathrm{CaCO}_{3}$ powder under thorough rubbing with a spatula. The amount of oil required to achieve the desired endpoint was used to calculate the oil absorption value.

X-ray diffraction (XRD) (Empyrean, Malvern Panalytical, Worcestershire, UK) patterns of the coatings were obtained in continuous scanning mode at a step size of $0.0131^{\circ}$ and operating conditions of $45 \mathrm{kV}$ and $40 \mathrm{~mA}$. The degree of crystallinity of the coatings was determined from the XRD patterns using the Match program.

Several methods for measuring the scratch resistance of polymers or polymer composites have been developed. Although the knife test (ASTM D6677) [55], pencil test (ASTM D3363) [56], and other standard evaluation methods (ASTM D4366) [57] can be used for this purpose, these tests do not sufficiently consider the complex responses of materials and have lost their status as methods linked directly to operator experience [9].

Scratch hardness is one of the most commonly used parameters for evaluating the scratch performance of materials and can be appropriately used to determine the susceptibility of polymeric materials to scratch deformation [48]. A scratch test involves the movement of an indenter of a specified geometry, subjected to a constant or progressive normal load, across a surface for a finite length at either constant or increasing speed [9]. The deformation that occurs during a scratch test is shown in Figure 1. As the conical indenter moves from left to right under load $N$ at speed $V$, the sequential accumulation and release of tangential force cause squeezing of the material that accumulates in front of the indenter as pile-up pads until the material reaches its elastic limit [58], finally leading to the formation of scratch tracks parallel to the direction of movement of the indenter [20]. The figure shows the contact depth $\left(h_{\mathrm{c}}\right)$, penetration depth $\left(h_{\mathrm{t}}\right)$, and scratch width $(w)$. 


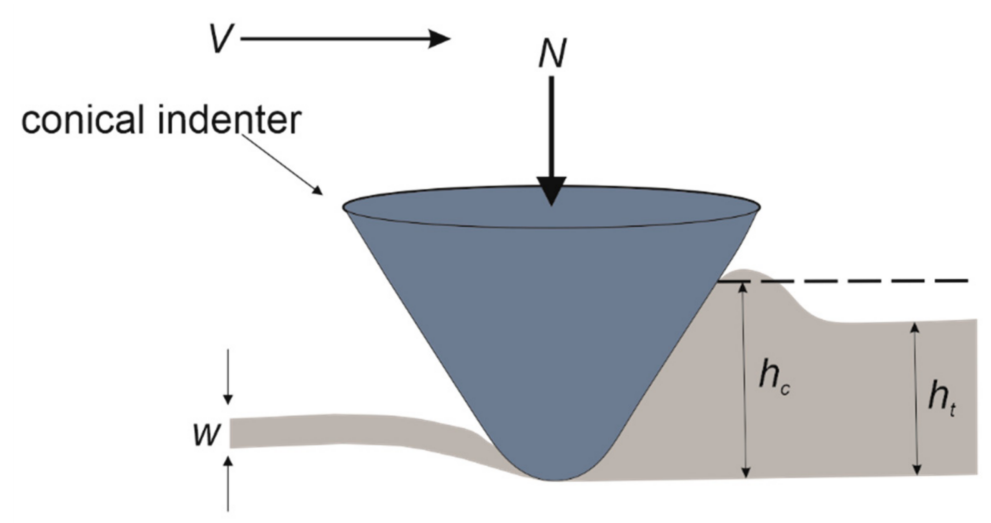

Figure 1. Schematic of deformation during the scratch test.

The scratch testing conditions of indenter geometry, normal load, temperature, and scratch velocity were held constant in this study, and the effect of $\mathrm{CaCO}_{3}$ mineral fillers of different particle sizes on the scratch behaviors of the coating surfaces under the same scratch test conditions was investigated. The tests were performed under a constant load of $\sim 12 \mathrm{~N}$ and the constant indenter tip speed of $\sim 5 \mathrm{~mm} / \mathrm{s}$. A micro-scratch tester equipped with a conical indenter with an apex angle of $136^{\circ}$ and a tip with a radius of $200 \mu \mathrm{m}$ was used to form a scratch with a total length of $15 \mathrm{~mm}$ for each test. Five scratches were obtained on each coating sample. All tests were performed at $23{ }^{\circ} \mathrm{C}$. At the end of each test, the profiles of the transverse and longitudinal sections of the scratch tracks were obtained using a contactless optical profilometer (Nanovea, PS50, Irvine, CA, USA). The morphologies of the scratch surfaces were characterized by scanning electron microscopy (SEM, EVO50, Zeiss, Oberkochen, Germany) equipped with a backscattered electron detector (BSD). The surfaces were coated with a layer of gold prior to SEM imaging to avoid charging.

The scratch test represents the average or global response of the material to the contact load exerted by the indenter [37]. Similar to the indentation hardness, the scratch hardness is calculated as the normal load divided by the projected load-bearing area $[8,20]$ :

$$
H_{\text {scratch }}=N_{\text {scratch }} / A_{\mathrm{p}}
$$

where $H_{\text {scratch }}$ is the scratch hardness $\left(\mathrm{kgf} / \mathrm{mm}^{2}\right), N_{\text {scratch }}$ is the normal load $(\mathrm{N})$, and $A_{\mathrm{p}}$ is the projected load-bearing area $\left(\mathrm{mm}^{2}\right) . A_{\mathrm{p}}$ can also be expressed as $\pi w^{2} / 4$ for a spherical indenter, where $w$ is the recovered width of the scratch. Thus, the scratch hardness is given by:

$$
H_{\text {scratch }}=\left(4 \times N_{\text {scratch }}\right) /\left(\pi w^{2}\right)
$$

According to Briscoe and Sinha [10], depending on the viscoelasticity of the material, a constant $q$ in the range $1-2$ can also be added to the formula:

$$
H_{\text {scratch }}=\left(4 \times q \times N_{\text {scratch }}\right) /\left(\pi w^{2}\right)
$$

However, because this value can be neither obtained experimentally nor predicted analytically, Briscoe's approach has been described as inadequate [37].

There are also different opinions when measuring the load-bearing area according to the indenter shape. While the classical approach accepts that only the front half of the indenter is in contact with the material, Pelletier [59] proposed a different model for viscoelastic-viscoplastic materials, such as polymers, in which the rear side of the indenter is also partly in contact with the material. However, in Pelletier's model, the rheological factor was also included in the calculations. In scratch hardness calculations using Pelletier's model, Kurkcu et al. [37] stated that the rheological factor alone cannot accurately describe the complexity of the scratch phenomenon. Other factors such as the 
flow properties of the material, strain hardening, and viscoelastic characteristics may have a considerable influence on the scratch behavior [37].

In this study, we calculated the scratch hardness using a scratch depth-dependent formula, which shows a good correlation with scratch roughness, as suggested by Hadal et al. [20]. We considered the relationship between the scratch width $(w)$ and scratch depth $(d)$ for the conical indenter with an angle of $136^{\circ}$, where $w=2 d / 0.404$. The constant $q$ in Equation (3) is assumed to be 1 . Thus, the scratch hardness $\left(H_{\text {scratch }}\right)$ is given by:

$$
H_{\text {scratch }}=\left(0.1632 \times N_{\text {scratch }}\right) /\left(\pi d^{2}\right)
$$

The scratch width $w$ and scratch depth $d$ were measured from the profiles of the scratch surfaces obtained using the profilometer. The penetration depth $h_{\mathrm{t}}$ shown in Figure 1 was used as the scratch depth $d$.

The areal parameters for roughness specified in ISO 25178 [60] were determined using an optical profilometer on the scratched coating surfaces. Measurements were performed for each sample over an area of $1920 \mu \mathrm{m} \times 9920 \mu \mathrm{m}$ for an average of 10 measurements. Several parameters can be used as a measure of the surface roughness, the most common of which is the arithmetical mean height of the profile or plane given as parameter $R_{\mathrm{a}}$ or $S_{\mathrm{a}}$, respectively. $S_{\mathrm{a}}$ is the extension of $R_{\mathrm{a}}$ (arithmetical mean height of a line) to a surface. In general, $S_{\mathrm{a}}$ is used to determine the surface roughness. However, $R_{\mathrm{a}}$ and $S_{\mathrm{a}}$ are inadequate for assessing the overall surface topography, as different surface profiles or areas can exhibit the same or similar $R_{\mathrm{a}}$ or $S_{\mathrm{a}}$, respectively [61-63]. If the varying heights along a profile or plane of a (rough) surface are considered as a distribution, it is possible to gauge whether a profile or plane is skewed towards broad peaks and spike-like valleys, or towards broad valleys and spike-like peaks. The parameters used to provide this information are the linear and areal skewness $R_{\mathrm{sk}}$ and $S_{\mathrm{sk}}$, respectively [62-64]. $S_{\mathrm{sk}}$ represents the degree of symmetry of the surface height of the mean plane. The sign of $S_{\mathrm{sk}}$ indicates the predominance of valleys $\left(S_{\mathrm{sk}}<0\right)$ or peaks $\left(S_{\mathrm{sk}}>0\right)$ on the surface [65-67]. In this study, the roughness $\left(S_{\mathrm{a}}\right)$ and skewness $\left(S_{\mathrm{sk}}\right)$ values were evaluated to characterize the coating surfaces after the scratch tests.

\section{Results and Discussion}

\section{1. $\mathrm{CaCO}_{3}$ Powder and Coating Characteristics}

The results of the analysis of the $\mathrm{CaCO}_{3}$ powder samples used as fillers in the coatings are given in Table 2. The grain size analysis shows the four different sizes of $\mathrm{CaCO}_{3}$ particles between 2.78 and $6.68 \mu \mathrm{m}$. The color measurement results show that all $\mathrm{CaCO}_{3}$ samples used have high lightness with $L^{*}$ values near 100. The fact that the $a^{*}$ and $b^{*}$ values both approach zero shows that $\mathrm{CaCO}_{3}$ powders contain no red, green, yellow, or blue colors and are therefore pure samples. These color values of $\mathrm{CaCO}_{3}$ enable the preparation of whiter paint formulations than those containing nepheline syenite as a filler [36].

Table 2. Properties of $\mathrm{CaCO}_{3}$ powders used in this study.

\begin{tabular}{ccccccccc}
\hline $\mathbf{C a C O}_{3}$ Sample & $\boldsymbol{d}_{\mathbf{5 0}}(\boldsymbol{\mu \mathrm { m } )}$ & $\boldsymbol{L}^{*}$ & $\boldsymbol{a}^{*}$ & $\boldsymbol{b}^{*}$ & Surface Area $\left(\mathbf{m}^{\mathbf{2} / \mathbf{g})}\right.$ & $\begin{array}{c}\text { DOP Oil Absorption } \\
(\mathbf{g} / \mathbf{1 0 0} \mathbf{g})\end{array}$ & $\begin{array}{c}\text { Flax Oil Absorption } \\
(\mathbf{g} / \mathbf{1 0 0} \mathbf{g})\end{array}$ \\
\hline Kal1 & 2.78 & 98.81 & -0.01 & 0.73 & 4.41 & 31.00 & 17.00 \\
$\mathrm{Kal2}$ & 3.47 & 98.87 & -0.01 & 0.59 & 3.25 & 31.00 & 16.00 \\
$\mathrm{Kal3}$ & 5.63 & 98.67 & 0.00 & 0.76 & 2.63 & 28.00 & 15.00 \\
$\mathrm{Kal} 4$ & 6.68 & 98.53 & 0.01 & 0.75 & 2.40 & 26.00 & 14.00 \\
\hline
\end{tabular}

In Table 3, the viscosity values of the prepared coatings measured in Krebs units and their equivalents in $\mathrm{mPa} \cdot \mathrm{s}$ are given. When finer grains of $\mathrm{CaCO}_{3}$ were used in the formulation, the viscosity of the prepared coating was increased. This is because the surface areas of the $\mathrm{CaCO}_{3}$ grains were increased owing to their smaller grain size (Table 2), creating more contact area with the resin and increasing the resin absorption capacity of 
the $\mathrm{CaCO}_{3}$ grains. As the grain size decreased, the DOP and flax oil absorption capacity of $\mathrm{CaCO}_{3}$ increased, supporting this hypothesis (Table 2).

Table 3. Viscosity values measured with the Krebs Stormer viscometer in Krebs units and its equivalents in $\mathrm{mPa} \cdot \mathrm{s}$.

\begin{tabular}{cccc}
\hline Coating Sample & Filler & Viscosity (KU) & Viscosity (mPa·s) \\
\hline Coat1 & Kal1 & 63.70 & 422 \\
Coat2 & Kal2 & 62.30 & 394 \\
Coat3 & Kal3 & 60.30 & 355 \\
Coat 4 & Kal4 & 60.00 & 350 \\
Coat5 & CaCO3-free & 50.60 & 184 \\
\hline
\end{tabular}

Figure 2 shows the $X R D$ patterns of the coatings. $X R D$ analysis showed the presence of $\mathrm{CaCO}_{3}$ in all coatings except the $\mathrm{CaCO}_{3}$-free coating (Coat5). The determined crystallinity percentages of Coat1, Coat2, Coat3, Coat 4 , and Coat 5 from XRD analysis were $54.99 \%$, $50.22 \%, 46.28 \%, 45.23 \%$, and $10.79 \%$. The higher-than-expected degree of crystallization $(10.79 \%)$ of Coat5 is thought to be due to the mineral-based additives (e.g., Texaphor) included in the formulation. Texaphor contains bentonite clay, the most important component of which is montmorillonite. The highest peak of dehydrated montmorillonite is around $6.5^{\circ}$; this appeared in the XRD profiles of the coatings, especially Coat5 (Figure 2).

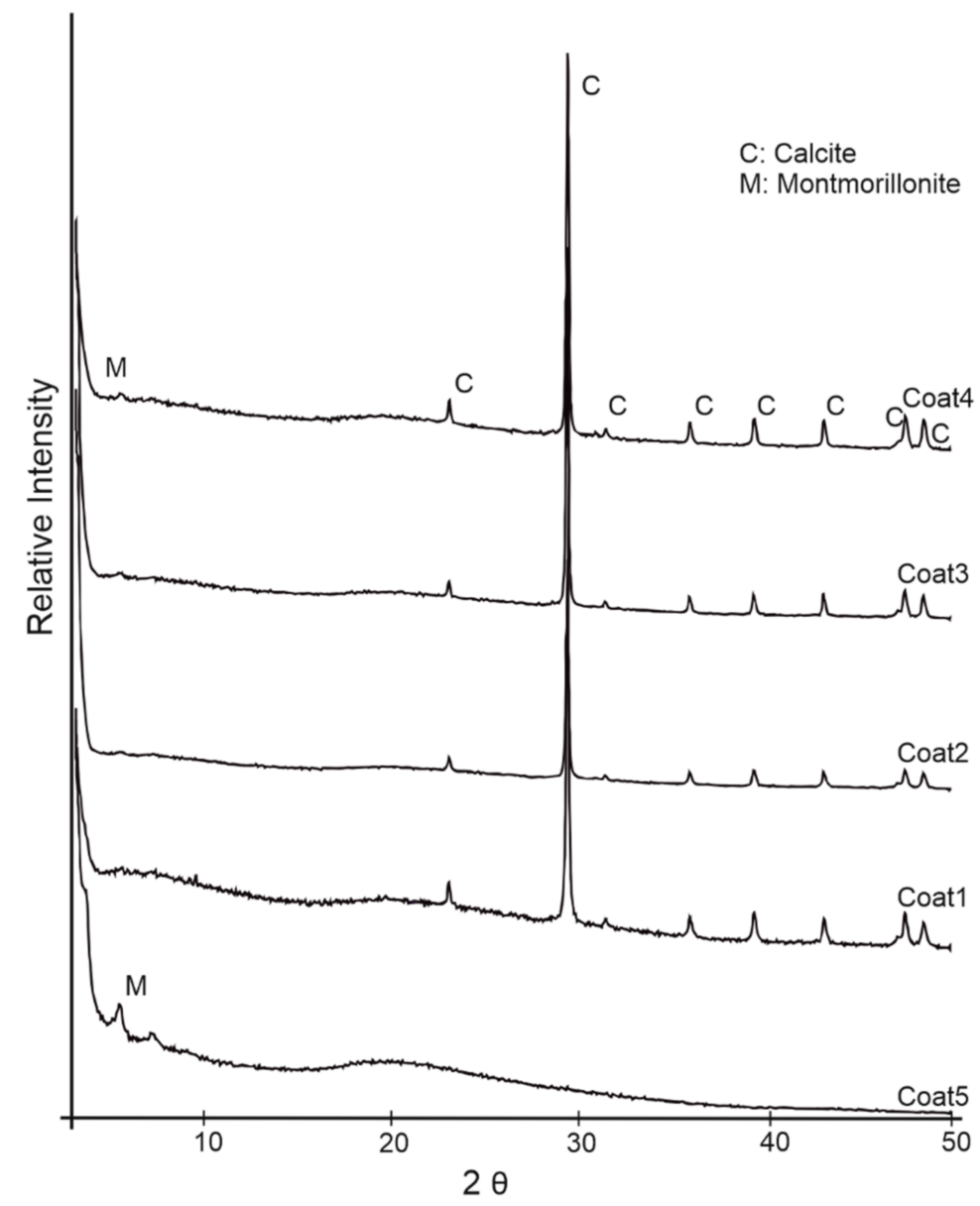

Figure 2. XRD patterns of coatings. 


\subsection{Scratch Morphology}

The scratch morphologies exhibited significant variations depending on the size of the $\mathrm{CaCO}_{3}$ used. When analyzing the $3 \mathrm{D}$ reconstructed scratch surfaces on coatings, it was observed that regular scratch marks were produced only on the coating surface containing the finest-grained $\mathrm{CaCO}_{3}$ (Coat1; Figure 3A). A wider scratch mark was formed on the Coat2 surface, and the distance between the scratch tracks was increased (Figure 3B). Zig-zag scratches on Coat1 and Coat2 had a sharp appearance with distinct boundaries between the scratched and unscratched regions (Figure 3A,B). As the grain size of $\mathrm{CaCO}_{3}$ increased further, wider and deeper valleys with no clear scratch patterns on the coating surfaces began to develop (Figure 3C,D). The $\mathrm{CaCO}_{3}$-free coating surface (Coat5) showed a wide scratch morphology as a result of the breakage of large pieces from the coating surface (Figure 3E). The SEM images also supported these findings (Figure 4).

SEM images of the scratch surfaces showed that if $\mathrm{CaCO}_{3}$ was not used or coarser $\mathrm{CaCO}_{3}$ grains were used, larger pieces of the coating were broken off the surface. Wide scratches were formed as a result of the rupture of large pieces on the $\mathrm{CaCO}_{3}$-free and coarser $\mathrm{CaCO}_{3}$-containing coating surfaces. This can be explained in two ways. The first is the low interfacial adhesion of the matrix and filler, and the second is the barrier function of the minerals in front of the crack tips. Owing to the extreme incompatibility between the nonpolar alkyd resin and the $\mathrm{CaCO}_{3}$ grains, whose surfaces were not coated or treated with any dispersion or coupling agent, the interfacial adhesion of the matrix and filler was poor, and voids were formed at the mineral-resin interface. The dimensions of these voids were greater at the interfaces of the matrix with coarser mineral particles (arrows in Figure 4D). In fact, the mineral particles acted as physical obstacles in front of the crack tips in the matrix. Higher deformation can also be correlated with the lower number of mineral particles per unit volume in coatings containing coarser grains. The number of grains per unit volume decreased with coarser grains assuming the constant mineral filler content of $25 \mathrm{wt} . \%$. Thus, the crack tip was more likely to propagate without encountering a mineral particle in the matrix and thus rupturing larger coating pieces. The similarity in the scratch characteristics of the coatings with coarser $\mathrm{CaCO}_{3}$ and the $\mathrm{CaCO}_{3}$-free coating (Figure 4) and the degree of crystallinity values calculated from the XRD data also support this. However, when finer grains were used, the number of grains per unit volume increased because of the dispersion of a large number of finer mineral grains in the resin. The crack tip was more likely to encounter a mineral grain as it propagated through the matrix. The lower degree of deformation in fine-grained $\mathrm{CaCO}_{3}$-containing coatings can also be explained by the improved interface between the resin and grains as a result of the higher surface areas of the fine-grained minerals (Table 2). In addition, large voids were not observed on the unscratched surfaces of coatings containing fine-grained $\mathrm{CaCO}_{3}$, and the surfaces appeared smoother (Figure 4). When investigating the deformation intensities and morphologies on the surface, it was observed that the scratch mechanism in Coat1 and Coat 2 was in the form of plastic plowing, but that in Coat 3 and Coat 4 was plastic plowing-tearing. 


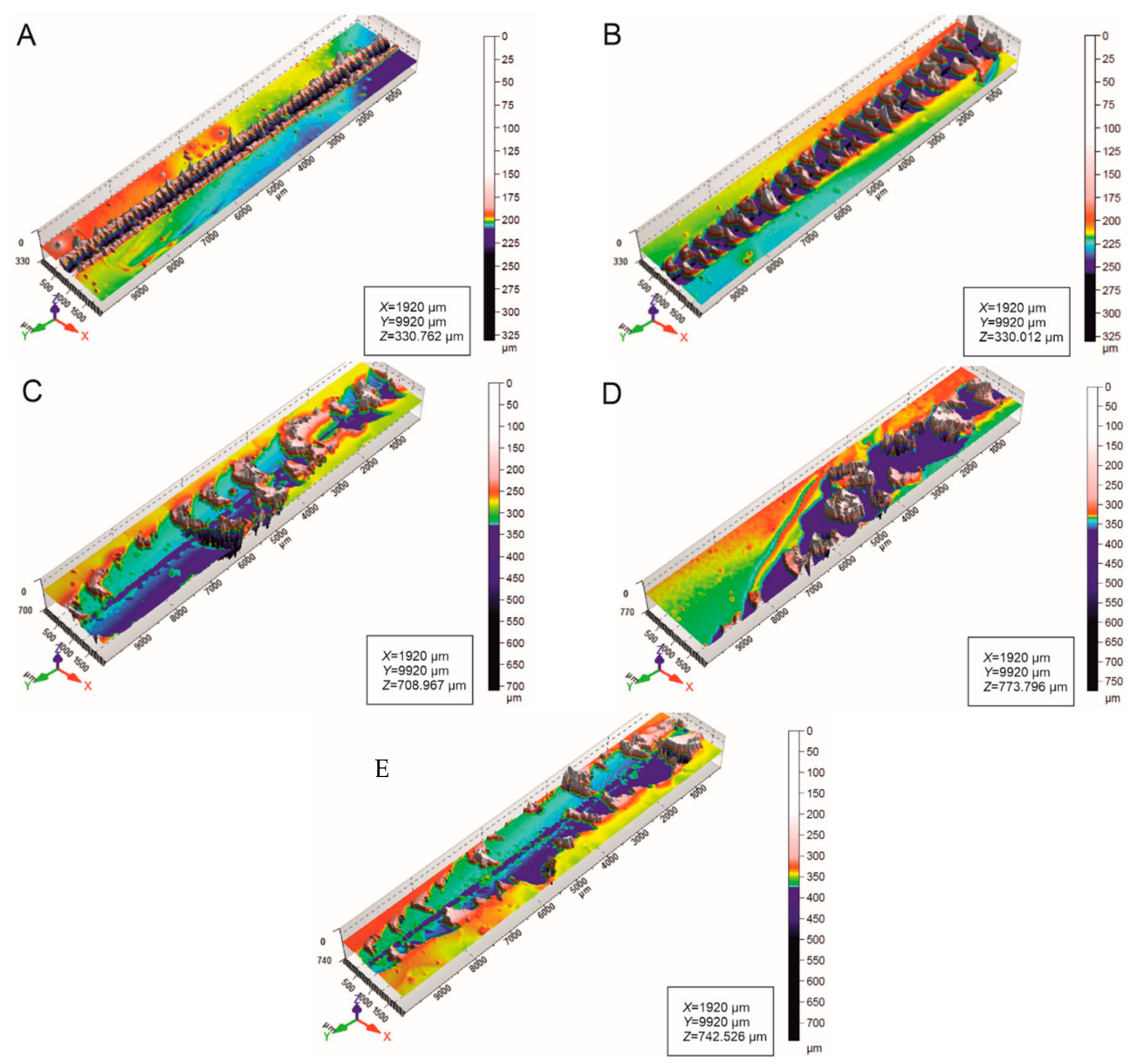

Figure 3. Three-dimensional (3D) reconstructed surfaces of scratch deformations on (A) Coat1, (B) Coat2, (C) Coat3, (D) Coat4, and (E) Coat5.
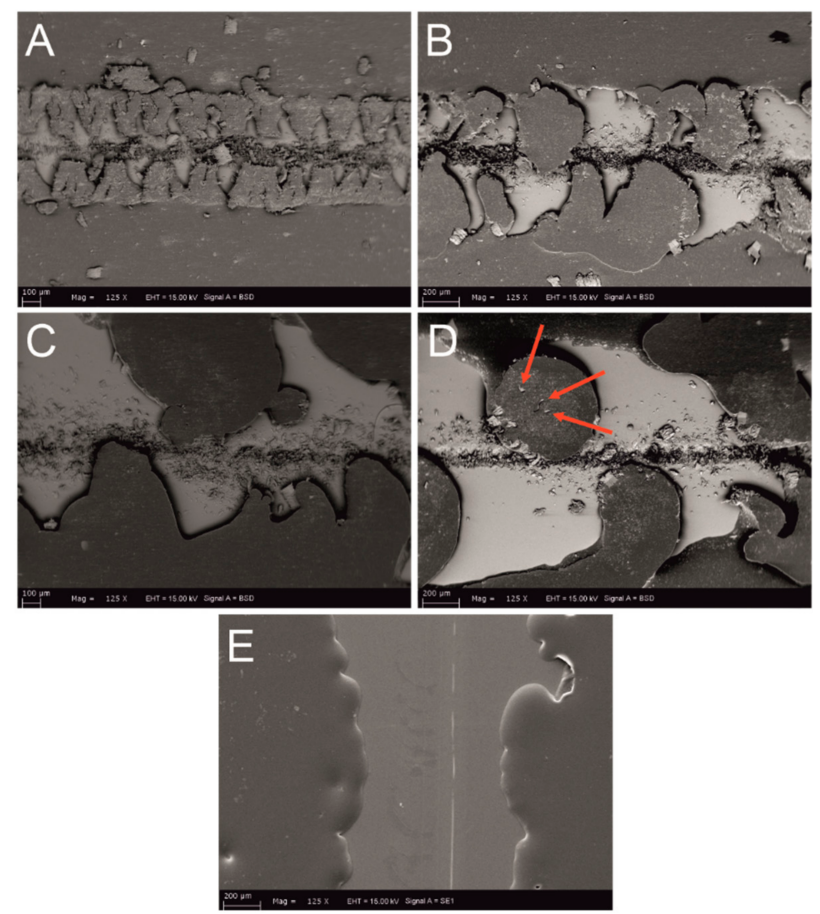

Figure 4. SEM micrographs of coating surfaces after the scratch test. (A) Coat1, (B) Coat2, (C) Coat3, (D) Coat4, and (E) Coat5. 
Increased deformation on the coating surfaces with increased filler grain sizes was also revealed by the scratch width and depth values measured using a profilometer (Figure 5). Both the widths and depths of the grooves formed on the coating surfaces increased with increasing grain size. The morphology of the scratch marks on the $\mathrm{CaCO}_{3}$-free coating surface (Coat5) was similar to those of the coating surfaces containing coarse-grained $\mathrm{CaCO}_{3}$ (Figure 6). Large cavities were formed in Coat3, Coat4, and Coat5 because of the large pieces that broke off their surfaces during scratching. As the $\mathrm{CaCO}_{3}$ grain size increases, the high variation in scratch depth and width values (see standard deviation bars in Figures 5 and 6) is interpreted to be caused by indenter "skips" on the surface during the test [21].

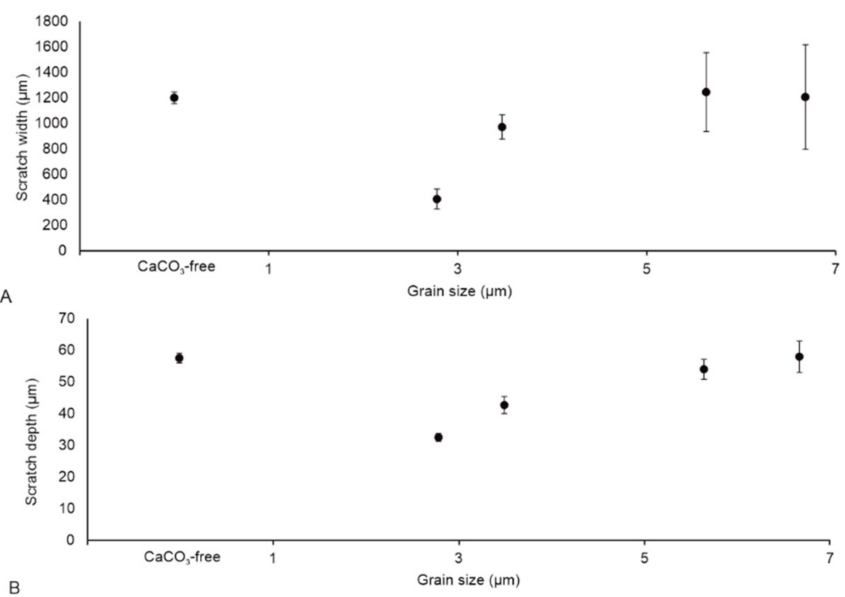

Figure 5. Scratch width $w(\mathbf{A})$ and scratch depth $d(\mathbf{B})$ values versus grain size of $\mathrm{CaCO}_{3}$ particles for scratch surfaces after the scratch test.
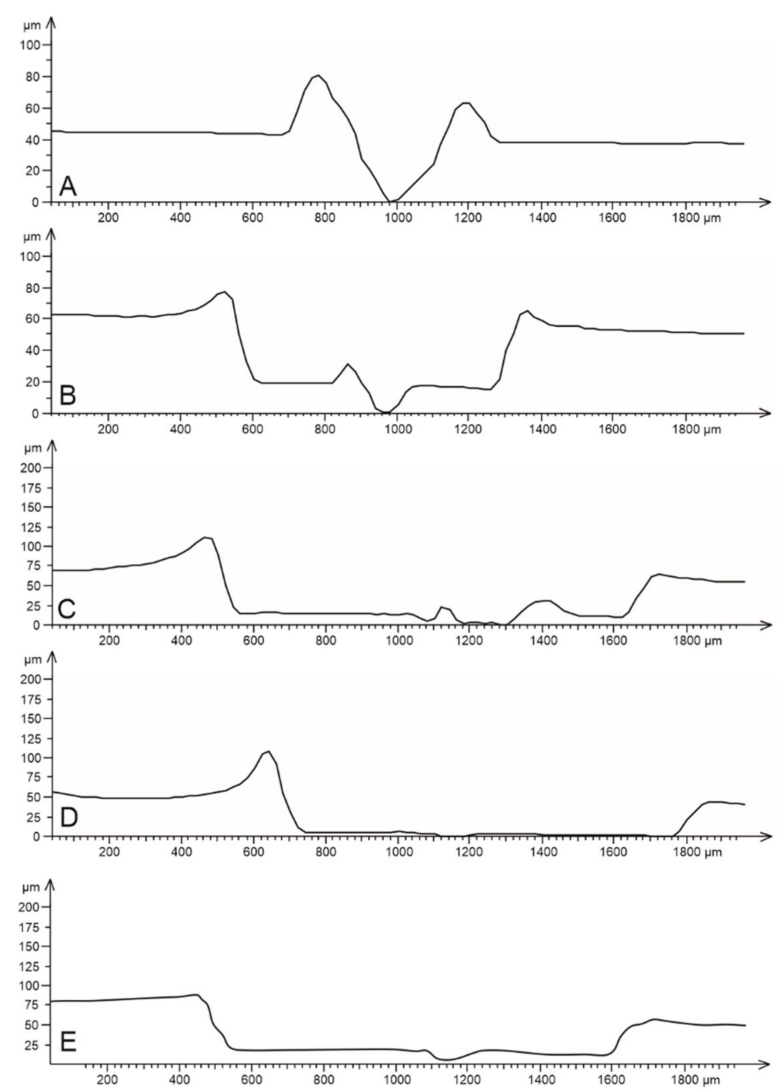

Figure 6. Extracted profiles from scratch surfaces. (A) Coat1, (B) Coat2, (C) Coat3, (D) Coat4, and (E) Coat5. 


\subsection{Scratch Hardness}

Scratch hardness can be used to determine the resistance of a material to scratch deformation. Materials with a higher scratch hardness are expected to exhibit greater resistance to scratch deformation. The scratch hardness values calculated according to Equation (4) revealed the effect of the grain size of $\mathrm{CaCO}_{3}$ used on the severity of deformation of coatings more clearly (Figure 7). It was observed that the surface resistance to scratching was decreased as the grain size of the filler increased. Deep grooves caused by large coating pieces breaking off the surface showed that these surfaces had low resistance to scratch deformation. In the obtained data, the scratch hardness values of the Coat3 and Coat 4 samples containing larger $\mathrm{CaCO}_{3}$ grains were similar, and it is expected that further increases in grain size would not cause significant changes in the scratch hardness, which appeared to reach a plateau (Figure 7). The similarity of the scratch hardness values of the $\mathrm{CaCO}_{3}$-free coating (Coat5) and the coating with the coarsest $\mathrm{CaCO}_{3}$ (Coat4) also indicated that coarser mineral particles did not affect the scratch hardness. However, the increase in scratch hardness values became greater with the use of finer $\mathrm{CaCO}_{3}$ grains (Figure 7). This explains the high scratch resistance of coatings containing nanometer-sized fillers $[1,4,8,9,17]$. Our scratch hardness results are in line with the pencil hardness test results made on paints containing $\mathrm{CaCO}_{3}$ [27]. Although the pencil hardness test can be applied easily and quickly, the test method used in this study is more advantageous due to the adjustable test conditions (e.g., indenter geometry, load, velocity). The common disadvantages are that the coating thickness affects the results of both methods.

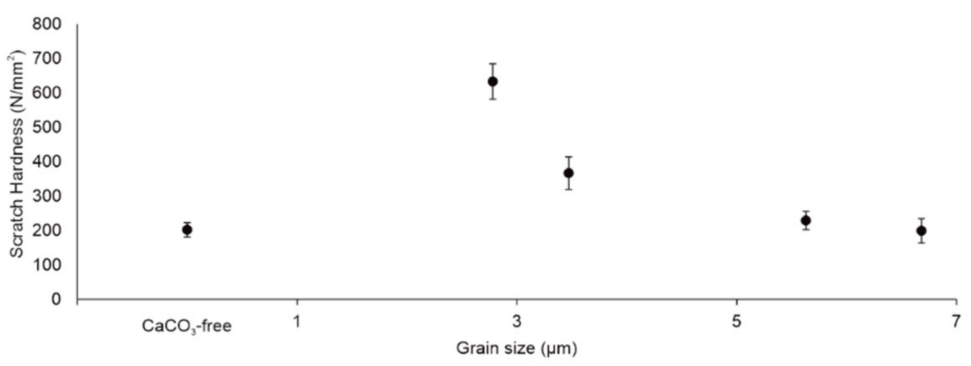

Figure 7. Scratch hardness versus grain size of $\mathrm{CaCO}_{3}$ particles for scratch surfaces after the scratch test.

\subsection{Roughness of Scratched Surfaces}

The roughness of each scratched surface showed an important correlation with the grain size of the $\mathrm{CaCO}_{3}$ used in the coating (Figure 8). As the grain size of $\mathrm{CaCO}_{3}$ increased, the roughness of the scratch surfaces increased. Extensive deformation due to the breakage of large coating pieces from the surface and the related wide and deep scratches caused an increase in roughness [68]. The higher roughness was also correlated with the lower number of particles per unit volume in the coatings using coarser grains. Resin with low scratch resistance became more susceptible to wear in more areas on the coating surface, as explained above. However, this can be explained by the lower-than-expected roughness of the $\mathrm{CaCO}_{3}$-free coating surface; the detached parts did not remain on the surface and did not affect the measurement, while the nonscratched coating areas were smoother than the mineral-containing coatings (Figure 4).

The roughness values measured on the scratched surfaces of the coatings showed a good correlation with the scratch hardness values calculated using the scratch depths, as suggested by Hadal et al. [20] (Figure 9). A similar relationship between scratch depth, scratch hardness, and surface roughness was observed in polypropylene materials containing mineral fillers [68]. 


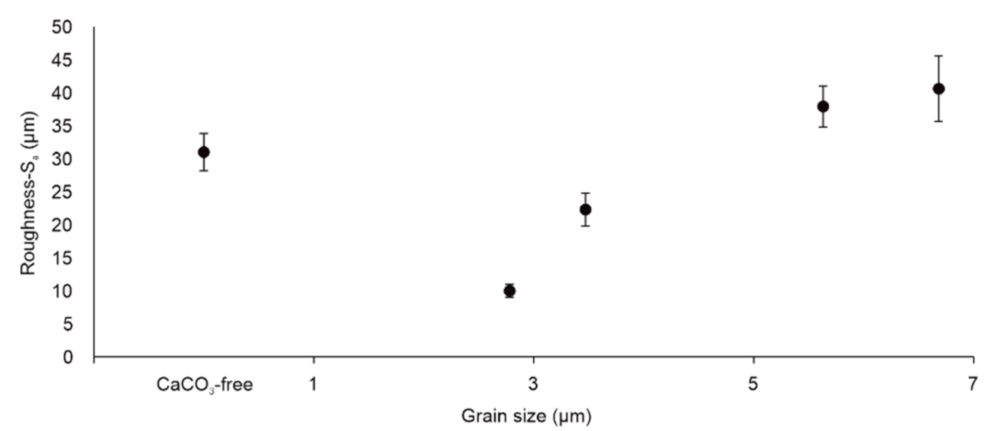

Figure 8. Roughness values $S_{\mathrm{a}}$ versus grain size of $\mathrm{CaCO}_{3}$ particles for scratch surfaces after the scratch test.

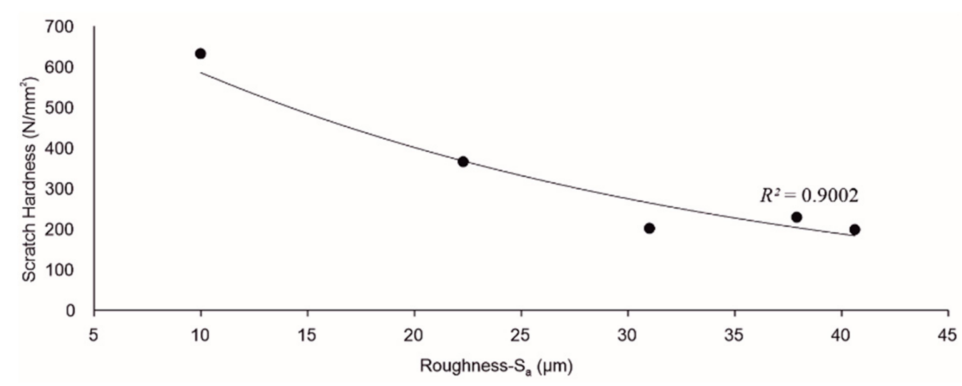

Figure 9. Roughness $S_{\mathrm{a}}$ versus scratch hardness of coating surfaces after the scratch test.

Depending on the grain size of the $\mathrm{CaCO}_{3}$ filler used, the skewness values of the scratched coating surfaces varied (Figure 10). The skewness values suggested that sharp peaks were formed on the scratch surfaces of coatings with fine-grained $\mathrm{CaCO}_{3}(\mathrm{Coat} 1$ and Coat2), while deep and sharp valleys were formed for those with coarser $\mathrm{CaCO}_{3}$ (Coat3 and Coat4; see the inset in Figure 10). The pile-up structures formed on Coat1 and Coat2, as a result of the material being squeezed out around the indenter via plastic deformation, had sharp peaks (Figure 6). The complicated, wide, and deep deformations that occurred on Coat 3 and Coat 4 caused the formation of valleys (Figure 6). The negative skewness values measured on the $\mathrm{CaCO}_{3}$-free coating surface indicated deformation-induced valleys, but this coating presented skewness values closer to zero owing to its smoother surface.

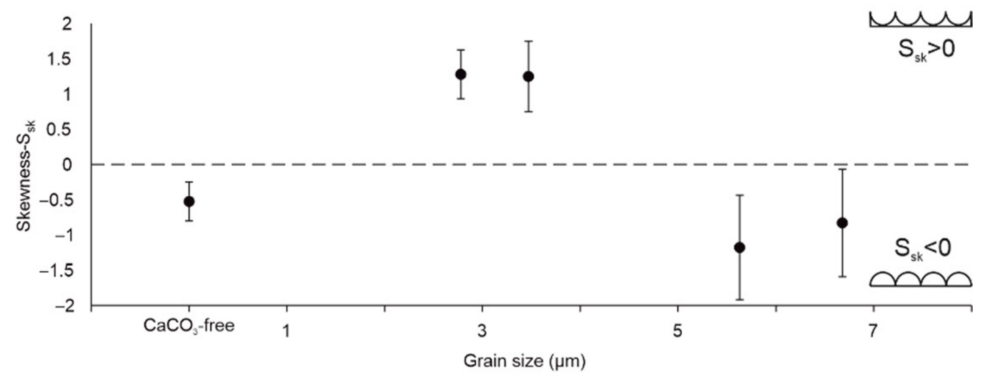

Figure 10. Skewness values $S_{\text {sk }}$ versus grain size of $\mathrm{CaCO}_{3}$ particles for scratch surfaces after the scratch test. Simple graphics showing surfaces with positive and negative $S_{\text {sk }}$ values are inset.

In scratching deformation, when the tensile stress behind the scratch exceeds the tensile strength of the polymeric material, plastic deformation is likely to occur [20]. It has been shown that coating surfaces with coarser $\mathrm{CaCO}_{3}$ are more prone to enhance plastic deformation. It is recommended that $\mathrm{CaCO}_{3}$ grains intended for use as filler in scratch-resistant coatings should be fine. The positive effects of the finer-grained $\mathrm{CaCO}_{3}$ fillers on the scratch resistance of the coatings could be further enhanced by treating or coating their surfaces with dispersing agents and/or coupling agents to improve their 
dispersion in and bonding/adhesion with the resin. It is known that modifying the surface of $\mathrm{CaCO}_{3}$ with dispersing agents such as stearic acid positively affects the dispersion of the particles in the coating and the properties of the coating [27].

Although recent studies show that $\mathrm{CaCO}_{3}$ can be replaced with nepheline syenite in cost-saving formulations in terms of opacity, abrasion resistance, burnish resistance, weatherability, and acid rain resistance [36], there is no study comparing two different filling materials in terms of scratch resistance, especially in wood coatings. This study reveals the importance of grain size in the scratch hardness performance of $\mathrm{CaCO}_{3}$ in rapid alkyd-based wood coatings, and there is a need for comparison studies with harder minerals in future studies.

\section{Conclusions}

It was shown that the scratch hardness values measured considering the scratch depth showed good correlations with the roughness of the coating surface after the scratch test. All coatings including $\mathrm{CaCO}_{3}$ showed better scratch resistance than $\mathrm{CaCO}_{3}$-free coatings. When finest-grained $\mathrm{CaCO}_{3}$ was used as a filler (Kal1), the surface of the rapid alkydbased wood coating (Coat1) underwent plastic plowing deformation in the form of regular, narrow, and shallow scratches, thus showing higher scratch resistance $\left(632 \mathrm{~N} / \mathrm{mm}^{2}\right)$. The finer-grained minerals used as fillers increased the filler-polymer interface area with their higher surface areas and improved the resistance to scratch damage. In addition, because the minerals in the matrix act as physical barriers to crack propagation, finer mineral particles increased the number of dispersed fine-grained minerals per unit volume of the coating and decreased free space in the resin, thus reducing the area susceptible to scratch deformation.

When coarsest $\mathrm{CaCO}_{3}$ was used as a filler (Kal4), the coating (Coat4) underwent more extensive plastic deformation as plowing-tearing owing to the weaker filler-polymer interface and lower scratch hardness $\left(199 \mathrm{~N} / \mathrm{mm}^{2}\right)$. Deeper and wider surface deformations occurred as the grain size became coarser owing to the larger coating particles that broke off the surfaces of the coatings, and larger resin areas were more susceptible to deformation.

Author Contributions: Methodology, investigation, supervision and writing, O.E.; profilometry analysis, S.F.; sample preparation, powder analysis H.K., D.G., and Ö.Ö. All authors have read and agreed to the published version of the manuscript.

Funding: This research was funded by NİĞ TAŞ Corporation.

Institutional Review Board Statement: Not applicable.

Informed Consent Statement: Not applicable.

Data Availability Statement: The data presented in this study are available in article.

Conflicts of Interest: The authors declare no conflict of interest.

\section{References}

1. Nikolic, M.; Lawther, J.M.; Sanadi, A.R. Use of nanofillers in wood coatings: A scientific review. J. Coat. Technol. Res. 2015, 12, 445-461. [CrossRef]

2. Flosbach, C.; Schubert, W. Zero etch clear-A new modular clear coat system with excellent scratch/mar performance. Prog. Org. Coat. 2001, 43, 123-130. [CrossRef]

3. Asif, M. Sustainability of timber, wood and bamboo in construction. In Sustainability of Construction Materials; Khatib, J.M., Ed.; CRC Press: Boca Raton, FL, USA, 2009; pp. 31-54. ISBN 9781845693497.

4. Chardon, F.; Denis, M.; Negrell, C.; Caillol, S. Hybrid alkyds, the glowing route to reach cutting-edge properties? Prog. Org. Coat. 2021, 151, 106025. [CrossRef]

5. Bauer, F.; Mehnert, R. UV curable acrylate nanocomposites: Properties and applications. J. Polym. Res. 2005, 12 , 483-491. [CrossRef]

6. Bauer, F.; Flyunt, R.; Czihal, K.; Buchmeiser, M.R.; Langguth, H.; Mehnert, R. Nano/micro particle hybrid composites for scratch and abrasion resistant polyacrylate coatings. Macromol. Mater. Eng. 2006, 291, 493-498. [CrossRef]

7. Vu, C.; Laferté, O. All layers count: Silica nanoparticles in the optimisation of scratch and abrasion resistance of high performance UV multi-layer coatings. Eur. Coat. J. 2006, 6, 34. 
8. Xiang, C.; Sue, H.J.; Chu, J.; Masuda, K. Roles of additives in scratch resistance of high crystallinity polypropylene copolymers. Polym. Eng. Sci. 2001, 41, 23-31. [CrossRef]

9. Sangermano, M.; Messori, M. Scratch resistance enhancement of polymer coatings. Macromol. Mater. Eng. 2010, $295,603-612$. [CrossRef]

10. Briscoe, B.J.; Sinha, S.K. Scratch resistance and localised damage characteristics of polymer surfaces-A review. Materialwiss. Werkst. 2003, 34, 989-1002. [CrossRef]

11. Jardret, V.; Morel, P. Viscoelastic effects on the scratch resistance of polymers: Relationship between mechanical properties and scratch properties at various temperatures. Prog. Org. Coat. 2003, 48, 322-331. [CrossRef]

12. Hancock, M.; Rothon, R.N. Principal types of particulate fillers. In Particulate-Filled Polymer Composites, 1st ed.; Rothon, R.N., Ed.; Smithers Rapra Press: Shrewsbury, UK, 2000; pp. 53-100. ISBN 1-85957-382-7.

13. Kurkcu, P.; Andena, L.; Pavan, A. An experimental investigation of the scratch behaviour of polymers-2: Influence of hard or soft fillers. Wear 2014, 317, 277-290. [CrossRef]

14. Bautista, Y.; Gonzalez, J.; Gilabert, J.; Ibañez, M.J.; Sanz, V. Correlation between the wear resistance, and the scratch resistance, for nanocomposite coatings. Prog. Org. Coat. 2011, 70, 178-185. [CrossRef]

15. Wang, Y.; Lim, S.; Luo, J.L.; Xu, Z.H. Tribological and corrosion behaviors of $\mathrm{Al}_{2} \mathrm{O}_{3}$ / polymer nanocomposite coatings. Wear 2006, 260, 976-983. [CrossRef]

16. Amerio, E.; Fabbri, P.; Malucelli, G.; Messori, M.; Sangermano, M.; Taurino, R. Scratch resistance of nano-silica reinforced acrylic coatings. Prog. Org. Coat. 2008, 62, 129-133. [CrossRef]

17. Douce, J.; Boilot, J.P.; Biteau, J.; Scodellaro, L.; Jimenez, A. Effect of filler size and surface condition of nano-sized silica particles in polysiloxane coatings. Thin Solid Films 2004, 466, 114-122. [CrossRef]

18. Bauer, F.; Sauerland, V.; Gläsel, H.-J.; Ernst, H.; Findeisen, M.; Hartmann, E.; Langguth, H.; Marquardt, B.; Mehnert, R. Preparation of scratch and abrasion resistant polymeric nanocomposites by monomer grafting onto nanoparticles, 3 . Effect of filler particles and grafting agents. Macromol. Mater. Eng. 2002, 287, 546-552. [CrossRef]

19. Tiwari, S.K.; Verma, K.; Saren, P.; Oraon, R.; de Adhikari, A.; Nayak, G.C.; Kumar, V. Manipulating selective dispersion of reduced graphene oxide in polycarbonate/nylon 66 based blend nanocomposites for improved thermo-mechanical properties. RSC Adv. 2017, 7, 22145-22155. [CrossRef]

20. Hadal, R.; Dasari, A.; Rohrmann, J.; Misra, R.D.K. Susceptibility to scratch surface damage of wollastonite- and talc-containing polypropylene micrometric composites. Mater. Sci. Eng. A 2004, 380, 326-339. [CrossRef]

21. Chu, J.; Xiang, C.; Sue, H.J.; Hollis, R.D. Scratch resistance of mineral-filled polypropylene materials. Polym. Eng. Sci. 2000, 40, 944-955. [CrossRef]

22. Lehmann, K.; Malacari, P.E. Polyolefin based compounds scratch resistance guaranteed by functional alliance of talc and additive used. In Proceedings of the Automotive TPO Global Conference, Detroit, MI, USA, 6-8 October 2008; SPE Detroit: Detroit, MI, USA, 2008; pp. 102-121.

23. Dasari, A.; Rohrmann, J.; Misra, R.D.K. On the scratch deformation of micrometric wollastonite reinforced polypropylene composites. Mater. Sci. Eng. A 2004, 364, 357-369. [CrossRef]

24. Zokaei, S.; Lesan Khosh, R.; Bagheri, R. Study of scratch resistance in homo- and co-polypropylene filled with nanometric calcium carbonate. Mater. Sci. Eng. A 2007, 445-446, 526-536. [CrossRef]

25. Tanniru, M.; Misra, R.D.K.; Berbrand, K.; Murphy, D. The determining role of calcium carbonate on surface deformation during scratching of calcium carbonate-reinforced polyethylene composites. Mater. Sci. Eng. A 2005, 404, 208-220. [CrossRef]

26. Tanniru, M.; Misra, R.D.K. Reduced susceptibility to stress whitening during tensile deformation of calcium carbonate-reinforced high density polyethylene composites. Mater. Sci. Eng. A 2006, 424, 53-70. [CrossRef]

27. Azadi, M.; Olya, M.J.; Vahedi, S.; Sangani, N.F. The effect of the chemical composition and the volume of coated carbonate calcium on epoxy paint properties. Russ. J. Appl. Chem. 2017, 90, 1181-1187. [CrossRef]

28. Yao, L.; Yang, J.; Sun, J.; Cai, L.; He, L.; Huang, H.; Song, R.; Hao, Y. Hard and transparent hybrid polyurethane coatings using in situ incorporation of calcium carbonate nanoparticles. Mater. Chem. Phys. 2011, 129, 523-528. [CrossRef]

29. Yan, X.; Qian, X.; Lu, R.; Miyakoshi, T. Synergistic effect of addition of fillers on properties of interior waterborne UV-curing wood coatings. Coatings 2018, 8, 9. [CrossRef]

30. Alvarez, V.; Paulis, M. Effect of acrylic binder type and calcium carbonate filler amount on the properties of paint-like blends. Prog. Org. Coat. 2017, 112, 210-218. [CrossRef]

31. Bulian, F.; Graystone, J. Wood Coatings, 1st ed.; Elsevier: Amsterdam, The Netherlands, 2009; ISBN 9780444528407.

32. Manias, E.; Touny, A.; Wu, L.; Strawhecker, K.; Lu, B.; Chung, T.C. Polypropylene/montmorillonite nanocomposites. Review of the synthetic routes and materials properties. Chem. Mater. 2001, 13, 3516-3523. [CrossRef]

33. Di Gianni, A.; Amerio, E.; Monticelli, O.; Bongiovanni, R. Preparation of polymer/clay mineral nanocomposites via dispersion of silylated montmorillonite in a UV curable epoxy matrix. Appl. Clay Sci. 2008, 42, 116-124. [CrossRef]

34. Piazza, D.; Lorandi, N.P.; Pasqual, C.I.; Scienza, L.C.; Zattera, A.J. Influence of a microcomposite and a nanocomposite on the properties of an epoxy-based powder coating. Mater. Sci. Eng. A 2011, 528, 6769-6775. [CrossRef] 
35. Pajarito, B.B.; Caguntas, A.J.F.; Felices, N.B.; Tubalinal, H.O.S.; Leuterio, G.L.D. Corrosion, wettability, and adhesion of acrylic coatings containing silane-treated mineral fillers on carbon steel. In Proceedings of the Materials Science Forum, Seoul, Korea, 20-22 October 2017; Argawal, R.K., Ed.; Trans Tech Publications Ltd.: Stafa-Zurich, Switzerland; Volume 917, pp. 252-256. [CrossRef]

36. Raper, S.; Skelhorn, D. Ground calcium carbonate versus feldspathic minerals. PCI Paint Coat. Ind. 2012, $28,66-71$.

37. Kurkcu, P.; Andena, L.; Pavan, A. An experimental investigation of the scratch behaviour of polymers: 1 . Influence of ratedependent bulk mechanical properties. Wear 2012, 290-291, 86-93. [CrossRef]

38. Krupička, A.; Johansson, M.; Hult, A. Use and interpretation of scratch tests on ductile polymer coatings. Prog. Org. Coat. 2003, 46, 32-48. [CrossRef]

39. Zhang, S.L.; Li, J.C.M. Slip process of stick-slip motion in the scratching of a polymer. Mater. Sci. Eng. A 2003, 344, 182-189. [CrossRef]

40. Gauthier, C.; Schirrer, R. Time and temperature dependence of the scratch properties of poly (methylmethacrylate) surfaces. J. Mater. Sci. 2000, 35, 2121-2130. [CrossRef]

41. Wong, M.; Lim, G.T.; Moyse, A.; Reddy, J.N.; Sue, H.J. A new test methodology for evaluating scratch resistance of polymers. Wear 2004, 256, 1214-1227. [CrossRef]

42. Rajesh, J.J.; Bijwe, J. Investigations on scratch behaviour of various polyamides. Wear 2005, 259, 661-668. [CrossRef]

43. Hara, Y.; Mori, T.; Fujitani, T. Relationship between viscoelasticity and scratch morphology of coating films. Prog. Org. Coat. 2000, 40, 39-47. [CrossRef]

44. Xiang, C.; Sue, H.J.; Chu, J.; Coleman, B. Scratch behavior and material property relationship in polymers. J. Polym. Sci. Part B Polym. Phys. 2001, 39, 47-59. [CrossRef]

45. Rodríguez, J.; Rico, A.; Soria, V. Tribological properties of commercial optical disks estimated from nanoindentation and scratch techniques. Wear 2007, 263, 1545-1550. [CrossRef]

46. Browning, R.L.; Lim, G.T.; Moyse, A.; Sue, H.J.; Chen, H.; Earls, J.D. Quantitative evaluation of scratch resistance of polymeric coatings based on a standardized progressive load scratch test. Surf. Coat. Technol. 2006, 201, 2970-2976. [CrossRef]

47. Hadal, R.S.; Misra, R.D.K. Scratch deformation behavior of thermoplastic materials with significant differences in ductility. Mater Sci. Eng. A 2005, 398, 252-261. [CrossRef]

48. Surampadi, N.L.; Pesacreta, T.C.; Misra, R.D.K. The determining role of scratch indenter radius on surface deformation of high density polyethylene and calcium carbonate-reinforced composite. Mater. Sci. Eng. A 2007, 456, 218-229. [CrossRef]

49. Moghbelli, E.; Browning, R.L.; Boo, W.J.; Hahn, S.F.; Feick, L.J.E.; Sue, H.J. Effects of molecular weight and thermal history on scratch behavior of polypropylene thin sheets. Tribol. Int. 2008, 41, 425-433. [CrossRef]

50. Briscoe, B.J.; Evans, P.D.; Biswas, S.K.; Sinha, S.K. The hardnesses of poly (methylmethacrylate). Tribol. Int. 1996, $29,93-104$. [CrossRef]

51. Wong, J.S.S.; Sue, H.J.; Zeng, K.Y.; Li, R.K.Y.; Mai, Y.W. Scratch damage of polymers in nanoscale. Acta Mater. 2004, 52, 431-443. [CrossRef]

52. Brostow, W.; Cassidy, P.E.; Macossay, J.; Pietkiewicz, D.; Venumbaka, S. Connection of surface tension with multiple tribological properties in epoxy + fluoropolymer systems. Polym. Int. 2003, 52, 1498-1505. [CrossRef]

53. Zarubica, A.; Miljkovic, M.; Purenovic, M.; Tomic, V. Colour parameters, whiteness indices and physical features of marking paints for horizontal signalization. Facta Univ. Ser. Phys. Chem. Technol. 2005, 3, 205-216. [CrossRef]

54. ASTM International. ASTM D281-12 Standard Test Method for Oil Absorption of Pigments by Spatula Rub-out; ASTM International: West Conshohocken, PA, USA, 2016. [CrossRef]

55. ASTM International. ASTM D6677-18 Standard Test Method for Evaluating Adhesion by Knife; ASTM International: West Conshohocken, PA, USA, 2018. [CrossRef]

56. ASTM International. ASTM D3363-20 Standard Test Method for Film Hardness by Pencil Test; ASTM International: West Conshohocken, PA, USA, 2020. [CrossRef]

57. ASTM International. ASTM D4366-14 Standard Test Methods for Hardness of Organic Coatings by Pendulum Damping Tests; ASTM International: West Conshohocken, PA, USA, 2014. [CrossRef]

58. Briscoe, B.J.; Evans, P.D.; Pelillo, E.; Sinha, S.K. Scratching maps for polymers. Wear 1996, 200, 137-147. [CrossRef]

59. Pelletier, H.; Mendibide, C.; Riche, A. Mechanical characterization of polymeric films using depth-sensing instrument: Correlation between viscoelastic-plastic properties and scratch resistance. Prog. Org. Coat. 2008, 62, 162-178. [CrossRef]

60. International Organization for Standardization. Geometrical product specifications (GPS)—Surface texture: Areal; International Organization for Standardization (ISO): Geneva, Switzerland, 2012; ISO 25178.

61. Fukumoto, M.; Nagai, H.; Yasui, T. Influence of surface character change of substrate due to heating on flattening behavior of thermal sprayed particles. J. Therm. Spray Technol. 2006, 15, 759-764. [CrossRef]

62. Patel, K.; Doyle, C.S.; Yonekura, D.; James, B.J. Effect of surface roughness parameters on thermally sprayed PEEK coatings. Surf. Coat. Technol. 2010, 204, 3567-3572. [CrossRef]

63. Bulaha, N. Calculations of surface roughness 3D parameters for surfaces with irregular roughness. In Proceedings of the Engineering for Rural Development, Jenglava, Latvia, 23-25 May 2018; Latvia University of Life Sciences and Technologies: Jenglava, Latvia, 2018; Volume 17, pp. 1437-1444. 
64. Stout, K.J.; King, T.G.; Whitehouse, D.J. Analytical techniques in surface topography and their application to a running-in experiment. Wear 1977, 43, 99-115. [CrossRef]

65. Ersoy, O.; Aydar, E.; Gourgaud, A.; Bayhan, H. Quantitative analysis on volcanic ash surfaces: Application of extended depth-of-field (focus) algorithm for light and scanning electron microscopy and 3D reconstruction. Micron 2008, 39, 128-136. [CrossRef]

66. Ersoy, O.; Gourgaud, A.; Aydar, E.; Chinga, G.; Thouret, J.C. Quantitative scanning-electron microscope analysis of volcanic ash surfaces: Application to the 1982-1983 Galunggung eruption (Indonesia). Bull. Geol. Soc. Am. 2007, 119, 743-752. [CrossRef]

67. Orkun, E. Analyse morphologique quantitative des cendres des dépôts pyroclastiques d'origine hydrovolcanique et magmatique. Ph.D. Thesis, Universite Blaise Pascal-Clermont Ferrand II, Aubière, France, 2012.

68. Chu, J.; Rumao, L.; Coleman, B. Scratch and mar resistance of filled polypropylene materials. Polym. Eng. Sci. 1998, 38, 1906-1914. [CrossRef] 